San Jose State University

SJSU ScholarWorks

Master's Projects

Master's Theses and Graduate Research

$5-24-2000$

\title{
The Relationship Between Companion Animals and Health Status Among Older Adults Living in the Community
}

Agnes M. Eytchison

San Jose State University

Follow this and additional works at: https://scholarworks.sjsu.edu/etd_projects

Part of the Geriatric Nursing Commons, and the Public Health and Community Nursing Commons

\section{Recommended Citation}

Eytchison, Agnes M., "The Relationship Between Companion Animals and Health Status Among Older Adults Living in the Community" (2000). Master's Projects. 850.

DOI: https://doi.org/10.31979/etd.by7g-5wgd

https://scholarworks.sjsu.edu/etd_projects/850

This Master's Project is brought to you for free and open access by the Master's Theses and Graduate Research at SJSU ScholarWorks. It has been accepted for inclusion in Master's Projects by an authorized administrator of SJSU ScholarWorks. For more information, please contact scholarworks@sjsu.edu. 
SAN JOSE STATE UNIVERSITY

a

SCHOOL OF NURSING

\section{MASTER'S PROGRAM PROJECT OPTION (PLAN B) \\ PROJECT SIGNATURE FORM}

STUDENT NAME

Agnes M. Eytchison

SEMESTER ENROLLED

Spruig 2000

TITLE OF PROJECT

The Relteinalif

Betureen Companion Anumalo

and Wealth status Among Clew Aduts

Luing is the Comonuity

NAME OF JOURNAL Amercain frunal Neuse Practitiones

The project and manuscript have been successfully completed and meet the standards of the School of Nursing at San Jose State University. The project demonstrates the application of professional knowledge, clinical expertise, and scholarly thinking. An abstract of the project and two copies of the manuscript are attached.

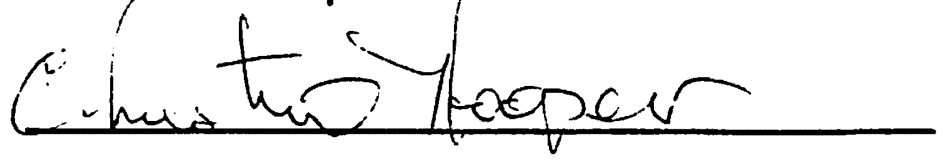

ADVISOR'S SIGNATURE

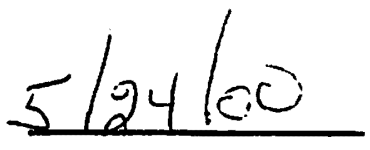

DATE

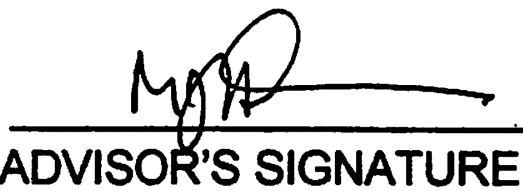

$\frac{5 / 24 / 00}{\text { DATE }}$

Please submit this form to the Graduate Coordinator. Attach abstract, two copies of the manuscript, and documentation of submission to the journal (i.e., postal receipt). 
Master Orals for May 17, 2000

The Relationship Between Companion Animals and Health Status Among Older Adults Living in the Community

Agnes Eytchison, RN, Candidate for MS and Family Nurse Practitioner

Readers: Christine Hooper, EdD, RN and M. J. Henderson, MS, RN, CS, GNP

\section{Abstract}

A study was conducted on 18 older adult pet owners and non-pet owners residing in a mobile home park to determine their self-perception of health status and level of attachment to pets. Self-reported health status was the same for both pet owners and non-pet owners. The level of attachment to the pets was very high.

Studies have shown human-animal interactions to benefit both individuals and families. However, the residents of the mobile home park and others in common interest developments such as condominiums and townhouse face pet restrictions and rules preventing many companion animal ownerships. Family Nurse Practitioners (FNP) aware of the benefits of animal companionship are in the position to advocate for elder clients when owning a companion animal would be therapeutic. Also, FNPs can be instrumental in helping to change legislation by educating and influencing lawmakers to enhance the mental and physical health of the elderly.

\section{Selected References from study}

Blackman, D. (1996). Furry friends fact sheet [On-line].

Available: http://www.furryfriends.org/patsfact.htm.

Chumley, P. R., Gorski, J. D., Saxton, A. M., Granger, B. P., New, Jr., J. C. (1994). Companion animal attachment and military transfer. Anthrozoos, 4, 258-273.

Lago, D., Knight, B., \& Connell, C. (1983). Relationships with companion animals among the rural elderly. In Wilson, C. C., \& Netting, F. E. (1987). New directions: Challenges for humananimal bond research and the elderly. The Journal of Applied Gerontology, $6,189-200$. 
Raina, P., Waltner-Toews, D., Bonnett, B., Woodward, C., \& Abernathy, T. (1999).

Influence of companion animals on the physical and phychological health of older people: An analysis of a one-year longitudinal study. Journal of the American Geriatric Society, 47, 323329.

Robin, M., \& ten Bensel, R. (1985). Pets and the socialization of children. Marriage and Family Review, 8, 63-78.

Wilson, C. C. \& Netting, F. E. (1987). New directions: Challenges for human-animal bond research and the elderly. The Journal of Applied Gerontology, 6, 189-200.

Wilson, C. C. \& Turner, D. C. (1998). Companion animals in human health. Thousand Oaks, CA: SAGE Publications, Inc.

AB 860 The Pets in Housing Bill: Please write to Senator Adam Schiff urging his support for this important piece of legislation as a healthcare provider. Senator Adam Schiff, Chair Senate Judiciary Committee Author of $\mathrm{AB} 860$ State Capitol Building Assemblywoman Helen Thomson
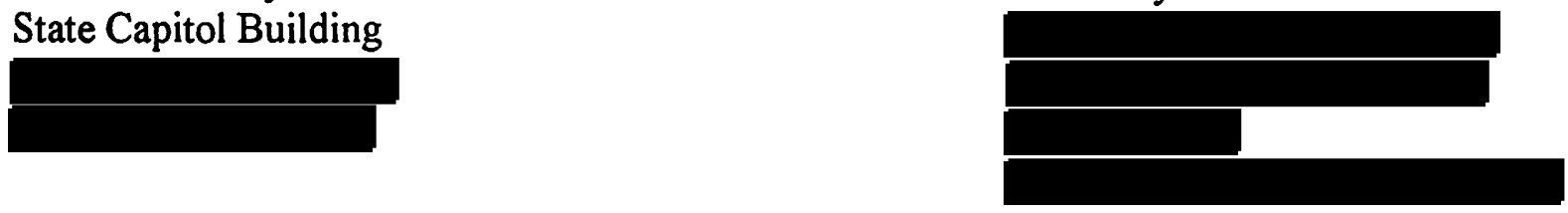
AMONG OLDER ADULTS LIVING IN THE COMMUNITY

*Agnes Eytchison, MS, RN, FNP

Christine Hooper, EdD, RN

Associate Professor

M. J. Henderson, MS, RN, CS, GNP

Lecturer

San Jose State University

School of Nursing

May 24, 2000 


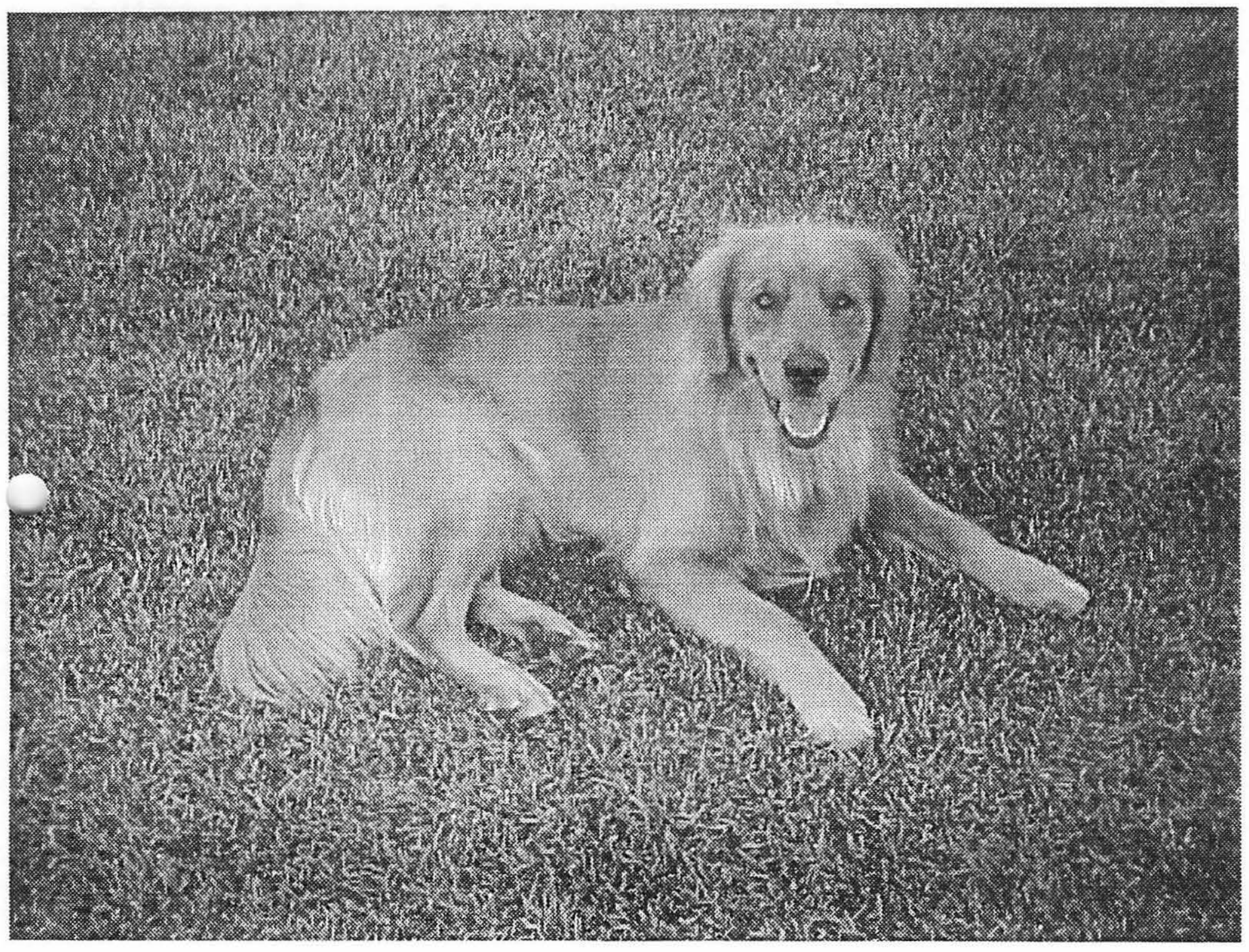

BUCK 2 1/2 year old Golden Retriever

(Color photo available on disc as a JPEG file) Companion Animal.JPEG 


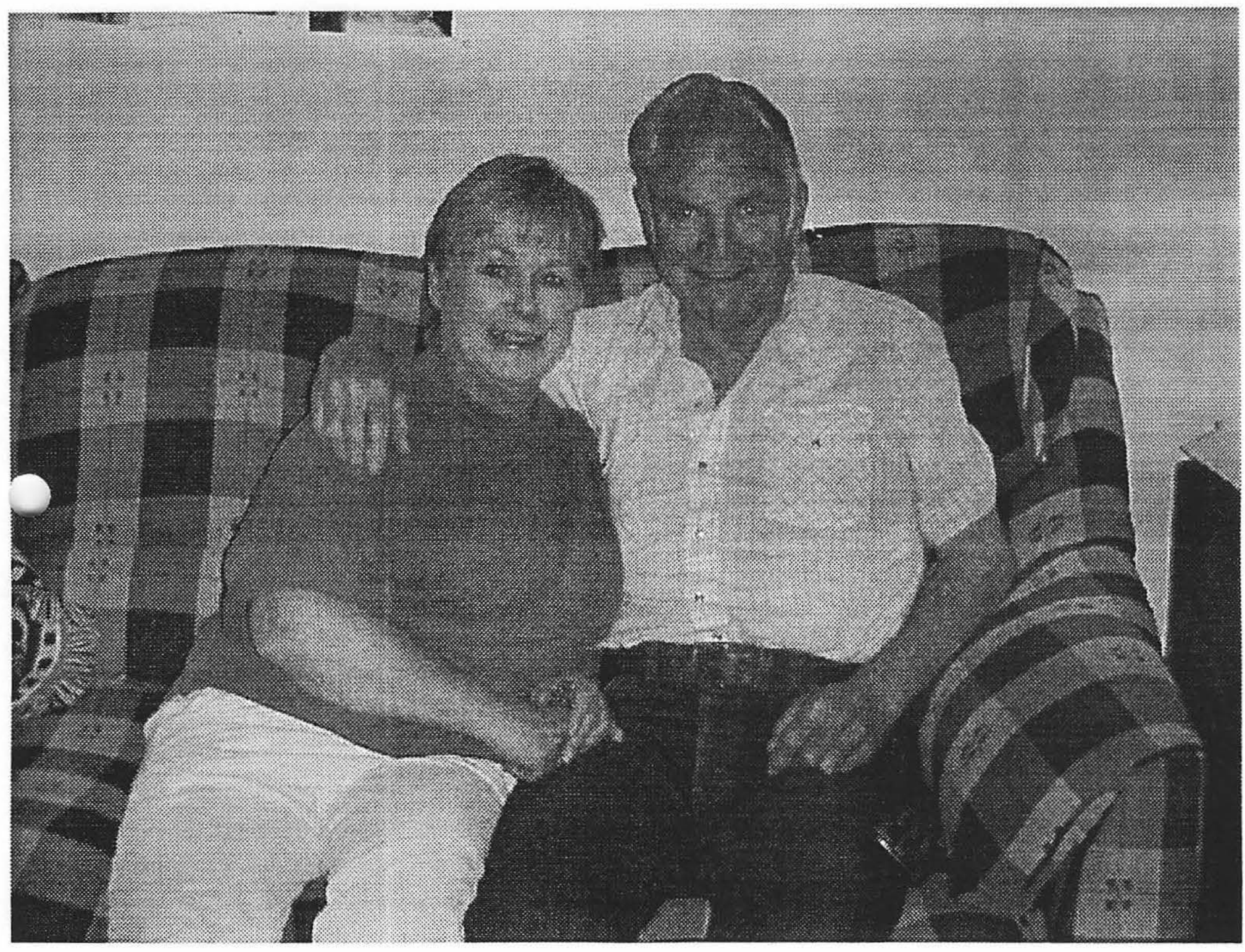

Jean and Richard Taylor

(Color photo available on disc as a JPEG file) Older Couple.JPEG 


\begin{abstract}
A study was conducted on 18 older adult pet owners and non-pet owners residing in a mobile home park to determine self-perception of health status and the level of attachment to pets. Self-reported health status was high and equal for both pet owners and non-pet owners. The level of attachment to the pets was also high.

Studies have demonstrated human-animal interactions being beneficial to both individuals and families; but for many residents of mobile home parks and common interest developments, such as condominiums and townhouses, rules prevent companion animal ownership. Family Nurse Practitioners (FNPs) aware of the benefits of animal companionship, are in a position to advocate for older patients, especially when owning a companion animal would be therapeutic. FNPs can be instrumental in helping to change state legislation by educating and influencing lawmakers about the benefits of pet ownership in the community dwelling older adult.
\end{abstract}




\section{Introduction}

In today's changing milieu of health care, more individuals are seeking complementary or alternative health care therapies. Consequently, Western medicine, traditionally embracing the allopathic system of health care, has become more amendable to these holistic therapies. These therapies focus on the whole person in the area of disease prevention, alleviation of health problems, and the management of symptoms. Equally important, many of these therapies facilitate personal choice, responsibility, and proactive patient participation (Snyder \& Lindquist, 1998).

Wilson \& Turner (1998) conducted a study to examine the evolving field of humananimal interactions (HAI) as a complementary therapy to illness prevention and wellness promotion. According to Wilson and Turner, studies have shown "animal contact could be healthy, contribute to child development of nurturance and self-concept, promote dialogue among family members, children, people with disabilities, and lonely people. It could contribute to physiological well-being and improvement of select cardiovascular markers, and reduce anxiety levels" (Wilson \& Turner, p.xi). Other studies have shown that the relationship or level of attachment between owner and pet is what makes the difference in positive influences on health (Beck \& Katcher, 1983; Serpell, 1991). The health and social benefits of pets have been demonstrated on mentally and physically ill people in hospitals, institutions, and long-term care facilities (Anderson, Reid, \& Jennings, 1992; Churchill, Safaoui, McCabe, \& Baun, 1999). The implications are that relatively healthy people would also benefit from contact with a pet (Beck \& Katcher; Bodmer, 1998; Robinson, 1999; Wilson, 1991). Accordingly, this study focused on a relatively healthy population of independently living older adults in the community. 
Dr. Leo K. Bustad, DVM, was a pioneer in promoting the human companion animal bond. He established the nationally recognized Delta Society in 1977 to study human-animal relationships and how they may be used to facilitate therapy (Bauer, 1993). Dr. Bustad stated, "I believe the day is coming when doctors will sometimes 'prescribe' pets instead of pills ... What pill gives so much love, makes one feel safe, stimulates laughter, encourages regular exercise and makes a person feel needed?" (Bauer, p.253). According to Cusack (1988), other professionals who recognize the benefit of HAI have been judicially prescribing or encouraging the use of pets since the early 1970s such as Dr. Michael McCulloch, psychiatrist and former vice president of the Delta Society. Dr. McCulloch stated, "Prescription of pets is a very tricky situation; you need to be cautious and sensitive to the social, economic, and psychological status of an individual. The therapeutic value of pets is self-evident. Research is showing animals have tremendous value in promoting humor, laughter and play, and in promoting a sense of importance. They make people feel significant" (Cusack, p.5).

Family nurse practitioners (FNPs) utilize critical judgment in performing comprehensive health assessments and furnishing pharmacological and non-pharmacological treatments to manage acute and chronic illness, and to promote wellness, health maintenance, and comfort (American Nurses Association, 1996). As primary health care providers, FNPs can assess the importance of pets to the patient and can use knowledge of human-animal interactions to complement traditional therapy.

Although pet therapy is known more extensively in Gerontological literature, its' efficacy is not well documented in FNP literature. The purpose of this study was to highlight the benefits of pet therapy for FNPs. This study compared the self-perceived health status of pet-owning older adults (i.e., people over 55 years of age) living in a mobile home park in the San Francisco 
Bay area, with the self-perceived health status of older adults living in the same park who did not own pets. The research question was as follows: Do older adults living independently in the community who own pets score higher on a health status index than older adults living in the same community who do not own pets?

\section{Conceptual Framework}

This research study used a quality of life approach as a conceptual framework to determine if older adults living independently in the community who own pets score higher on a health status index than older adults living in the same community who do not own pets.

Wilson (1994) and Lago (1998) suggested a quality of life approach for assessing humananimal interaction benefits. The author referred to quality of life as "clinically relevant aspects of subjective symptoms, feelings, and well-being" (Wilson, p.62) that can be measured by a broad view of health status. Wilson further suggested ten domains to measure and define quality of life in research patients. The domains are (a) physical status and symptoms, (b) functional status, (c) role activities, (d) social activities, (e) emotional status, (f) cognition, (g) sleep and rest, (h) energy and vitality, (i) health perceptions, and (j) general life satisfaction/well-being (Wilson, p. 67).

The instrument Short-Form Health Survey (SF-36) (Shiely, Bayliss, Keller, Tsai, \& Ware, 1996) was used in this study to measure perceived health status. Its' conceptual framework is based on quality of life aspects such as physical and mental health, activities of daily living (ADL), and well-being concepts of health. Values of the individual and perceived well-being are defined in terms of "well-proven self-reports of the frequency and intensity of feeling states including general mental health (psychological distress and psychological wellbeing), bodily pain, and vitality (energy and fatigue)" (Sheiley et al., p. 3.2). 


\section{Literature Review}

From popular magazines (Schindehette \& Wescott, 1999), newspapers (Goldston, 1999), and books to professional journals (Brickel, 1979; Corson S., Corson E., Gwynne, \& Arnold, 1977; Zissleman, Rovner, Shmuely, \& Ferrie, 1996), research data can be found regarding the beneficial effects and results of HAI (Bauer, 1993; Fick, 1993; Price, 1996). The information is extensive and ranges from guidelines to establishing a pet therapy program (Teeter, 1997; Westbrook \& Katz, 1985), to housing and logistics of animal care, (Blackman, 1996; Heath, 1999), and using pet therapy for elders and children in hospital and long-term facilities (Robin \& ten Bensel, 1985; Triebenbacher, 1998).

One study (Kongable, Stolley, \& Buckwalter, 1990) documented nursing staff's feelings and attitudes towards the responsibility of caring for a therapy dog. The authors recognized implications that had a direct bearing on the quality of life of patients with Alzheimer's disease (AD). Subjects showed improvement in social behavior and personal environmental interactions became more meaningful and balanced. For example, when the therapy dog was around the patients were more cheerful and interactive with one another (i.e., laughing, conversing, and singing). Staff also noted patients exhibited increased self-esteem and self-control (Kongable et al.).

Churchill et al. (1999) demonstrated similar quality of life concepts by examining the effects of a therapy dog on socialization and agitation exhibited by patients with $\mathrm{AD}$. For some $\mathrm{AD}$ patients, a phenomenon known as sundown syndrome occurs. Behavioral and verbal changes evidenced in part by "confusion, increased restlessness, aimless wandering, and agitation" (Churchill et al., p.16) often occur with increased frequency in the late-afternoon hours. The study revealed socialization had improved and agitation was decreased in the patients' behavior 
with the short-term presence of the therapy dog thus improving the quality of life for these $\mathrm{AD}$ patients. Furthermore, Kongable et al. (1990) and Wilson \& Turner (1998) noted the therapy dogs provide affection and companionship to patients regardless of cognitive or physical capacity.

Raina, Waltner-Toews, Bonnett, Woodward, and Abernathy (1999) in a one year longitudinal study of independent older people investigated whether companion animals or attachments to companion animals could be associated with changes in physical and psychological health. Additionally, the study determined whether or not the presence or absence of a companion animal modified the relationships between health status and human social networks. The study demonstrated the benefits of pet ownership in maintaining or slightly enhancing activities of daily living (ADL). Dog and cat pet owners had higher ADL scores than non-pet owners.

Friedmann, Katcher, Lynch, and Thomas (1980) conducted a prospective study on 92 coronary patients with a history of myocardial infarction to determine the relationship between pet ownership and one year survival status. Patients were interviewed in the hospital to ascertain social data and psychological mood status. After one year the survival status of the patients was investigated. Fifty pet owners survived compared to 28 non-pet owners; three pet owners died compared to 11 non-pet owners. Therefore, only one percent of pet owners with dogs died in the following year as compared to seven percent of non-pet owners.

Friedmann et al. (1980) noted that because more physical exertion and more extensive care and energy is required to care for dogs, pet ownership as a influential factor could be measured by the patient's physical status. Other research compared owners of pets (other than dogs) to non-pet owners to see any significance. Results showed a correlation between pet 
ownership and survival even with the dog type of pet factored out. Friedmann et al. confirmed the independent importance of social factors in determining health status such as employment variables and portion of life spent in urban areas. They further concluded health care professionals rendering care and management should consider the existence of pets as important factors for promoting wellbeing.

Additionally, Friedmann et al. (1980) noted a need for more research on the potential value of pets for companionship because nearly half of homes in the United States at that time had some kind of pet. Currently, the U. S. Census Bureau (1999) has determined since December 1996 more than 64 percent of all households in the United States own a companion animal; over 31 million households own a pet dog, 27 million own a pet cat, and 4.6 million own a pet bird.

\section{Study Method}

A cross-sectional integrated pilot study was conducted on independently living residents in one San Francisco Bay area mobile home park. The resident manager delivered a survey packet that respondents voluntarily completed and mailed back to the researcher. Each packet contained one health survey, a companion animal survey, and a return envelope. The purpose was to determine if older adults with pets would score higher on a health status index than older adults living in the same community who did not own pets.

\section{Sample}

Purposive sampling techniques were used based on three defined criteria: age, residence in the mobile home park community, and whether or not the respondents owned a pet. Residents in the mobile home park were 55 years of age or older. They indicated their marital status and whether or not they lived alone (i.e., with a spouse, relative, or friend). Eighteen respondents participated in this study. 


\section{Setting}

The mobile home park setting in this project has a pet policy whereby only residents occupying the mobile homes lining the outer boundaries of the park are allowed to have small dogs or cats approximately 20 pounds or less. Residents residing within the inner sections of the park are not allowed to have such pets, with the exception of fish, birds, reptiles, and small mammals like a hamster or guinea pig. Not all the pet owners in the mobile home park are permitted to have pets in residence. Because the survey was confidential, it was hoped that all the pet owners would participate in this study.

\section{Instruments}

\section{Health survey}

The general health status of the respondents was measured using the Short-Form Health Survey (SF-36) from the Health Institute, New England Medical Center in Boston. The SF-36 has been used extensively in health research and its reliability and validity has been established in multiple studies (Shiely et al., 1996). The SF-36 gathers a broad view of health with measures of physical functioning and role limitations, mental health, social functioning, vitality, and general health divided into eight scales (Gorin \& Arnold, 1998) as a measure of quality of life. On this 36 item questionnaire, respondents indicated perceived health status choosing, on a Lichert scale, items ranging from excellent to poor, better to worse, and all of the time to none of the time (Shiely et al.). Included was a brief demographic data portion used to collect information about age, race or ethnic background, marital status, and living arrangements. 


\section{Pet survey}

A separate Companion Animal Survey (CAS) was included for respondents who owned a pet or companion animal. The CAS was developed in a research study to measure the levels of attachment as a predictor of well-being between companion animals and military personnel experiencing a transfer to another military base (Chumley, Gorski, Saxton, Granger, \& New, 1994). The CAS uses a nine point semantic differential scale to assess perceived attachment to the favorite pet. This differential scale is followed by a 21 -item pet attachment scale from which respondents chose answers on a scale from "strongly agree" to "strongly disagree". This differential scale was included to further validate the 21 -item pet attachment scale. The authors determined an internal reliability (Cronbach's Alpha) for the 21 -item pet attachment scale from three preexisting companion animal attachment subscales (Chumley, et al.).

\section{Procedure}

The manager of the mobile home park delivered separate survey packets to all 106 residents along with the park's newsletter. Of the 34 surveys returned by mail, nine were pet owners who completed the Companion Animal Survey form in addition to the SF-36 Health Survey. Of the 22 non-pet owner health surveys returned, nine were randomly selected for the purpose of the t-test analysis to compare with the nine pet owners.

\section{Results}

\section{Demographics}

The pet owner respondents' $(n=9)$ ages ranged from 56 to 86 years of age with an average of 70 years of age. All of the pet owners were Caucasian. Three were married and living with their spouse; five were widowed and lived alone; one was divorced and lived with a friend. 
The non-pet owner respondents' $(n=9)$ ages ranged from 59 to 82 years of age with an average of 73 years of age. Eight of the non-pet owners were Caucasian and one respondent indicated a Spanish origin. Four were married living with their spouses; three were widowed and lived alone; and two indicated divorce status living alone.

\section{Health Survey}

The data were analyzed using the Statistical Package for Social Sciences. Group statistics for the SF-36 Health Survey were divided into the eight scale functioning categories with each mean and standard deviation between the two groups of pet owners and non-pet owners. The research question was to determine if older adults with pets would score higher on a health status index than older adults living in the same community who did not own pets. There was no statistical difference in scores on the SF-36 between pet owners and non-pet owners as measured between the means for all eight scales (Table 1A).

An independent sample t-test was used to determine the difference between the health status means of the pet owners and non-pet owners (Table 1B). However, the t-values yielded no statistical significance on any of the eight scales.

\section{Pet Survey}

The Companion Animal Survey indicated all the pet owners were equally attached to their pets either strongly or very strongly as measured by the differential scale. The majority (77 percent) indicated the highest level of attachment (very strong) and 23 percent showed a strong attachment. In response to the 21 items on the CAS, the pet owners had a possible score of 21 (least involvement with pet) to 186 (most involvement with pet). The scores ranged from 65 to 119 with a mean of $103(n=9)$. Collectively, the CAS indicated five owners had a pet cat (one or 
more) and the other four owners had a pet dog. One of the dog owners indicated there was also a parrot in the household.

\section{Discussion}

The research question was to determine if older adults who owned pets and lived independently in the community would score higher on a health status index than older adults living in the same community who did not own pets. Due in part to the small sample size, there was no statistically significant difference in scores on the SF-36 between the pet owners and non-pet owners' perceived health status. However, the means on six of the eight scales indicating better self-perceived health status were slightly higher for pet owners. Additionally, research studies have shown that the determinants of pet ownership are best identified over the life span of the elderly (Lago, 1998; Wilson \& Netting, 1987). In this study there was a time constraint preventing such a longitudinal study.

It is of interest to note that the only respondents to the survey were English reading and speaking. Except noting that all pet owners represented were Caucasian, there were not sufficient data in the demographics to make any ethnicity correlation between pet owners and non-pet owners. However, a future study of the cultural aspects of pet ownership in heterogeneous communities such as mobile home parks would be interesting.

Under the existing pet policy, potential respondents from the mobile home park were excluded from the CAS because they were not allowed to own a pet. Additionally, the control for confounding variables prevented the survey from extending to other senior mobile home parks because of the differences in pet policy. For example, residents were allowed to have a pet only if they had medical permission from their health care provider. For these reasons, the sample size was small. 


\section{Conclusion}

The companion animal pet restrictions placed on individuals residing in common interest developments such as mobile home parks was evident in this study. With the exception of service animals, i.e., seeing eye dogs, many pets in common interest developments overall are kept illegally without the knowledge of management. It is the observation of this researcher that this was the case in this research as well.

In California, state legislation is currently under consideration regarding the issue of companion animals. For example, Assembly Bill 860 (the Pets in Housing bill) was introduced by its author, a nurse, Assemblywoman Helen Thomson in December 1999 which states that no lease agreement made after January 1, 2000 can prohibit a homeowner from keeping a companion animal in a mobile home park. Additionally, AB 860 provides that after January 1, 2000 , new or amended governing documents for common-interest developments must also allow owners of a separate interest (such as condominium, apartment complex) to keep companion animals (Chris Tapio, personal communication, April 24, 2000).

Currently, federal and state laws uphold the rights of the elderly, and disabled individuals who live in subsidized rental housing, to have companion animals. However, ignorance of the law creates problems for individuals unaware of their rights as pet owners. Numerous health care providers write letters explaining the need for a companion animal; however, there is no law to uphold their counsel. The decision to accept or reject these medical recommendations is left to the agency owners and managers of common interest developments and conjugate housing.

California's AB 860 is considered a property rights issue where homeowners of common interest areas can own a pet yet are required to abide by reasonable rules and regulations to accommodate other residents. The requirement for a health care provider's recommendation to 
have a companion animal has been eliminated from this current bill. Consequently, AB 860's passage would remove the burden from individuals to obtain their health care provider's permission for a pet. Additionally, the law allowing pet ownership in common interest developments would protect more individuals who desire a companion animal.

Although the legislation ( $\mathrm{AB} 860$ ) is a California issue, this information would be of interest to FNPs in other states. For example, FNPs can advocate for patients by becoming involved in the political process regarding similar issues. FNPs can investigate existing laws and regulations and assess actual and potential problems regarding pet ownership for community dwelling older adults. Therefore, FNPs need to ask all older patients about pets and subsequently apply this information when planning care. The use of such therapeutic interventions as pet therapy can enhance quality of life for older adults. 
Table 1A

Independent Samples $\mathrm{t}$ - tests for 8 Scales (Group Statistics)

\begin{tabular}{|l|l|c|c|c|c|}
\hline \multicolumn{2}{|l|}{ GROUP } & $N$ & Mean & $\begin{array}{c}\text { Std. } \\
\text { Deviation }\end{array}$ & Std. Error \\
\hline PHYSICAL & & & & Mean \\
FUNCTIONING SCALE & PET OWNERS & 9 & 23.3333 & 5.2440 & 1.7480 \\
& NON-PET OWNERS & 9 & 23.4444 & 5.7252 & 1.9084 \\
\hline ROLE-PHYSICAL & PET OWNERS & 9 & 6.4444 & 1.7401 & .5800 \\
SCALE & NON-PET OWNERS & 9 & 5.8889 & 1.4530 & .4843 \\
\hline GENERAL HEALTH & PET OWNERS & 9 & 20.0444 & 5.1882 & 1.7294 \\
SCALE & NON-PET OWNERS & 9 & 18.1556 & 4.6495 & 1.5498 \\
\hline VITALITY SCALE & PET OWNERS & 9 & 16.1111 & 6.6416 & 2.2139 \\
& NON-PET OWNERS & 9 & 15.5556 & 3.5040 & 1.1680 \\
\hline SOCIAL & PET OWNERS & 9 & 8.6667 & 2.3979 & .7993 \\
FUNCTIONING SCALE & NON-PET OWNERS & 9 & 7.8889 & 2.0276 & .6759 \\
\hline ROLE-EMOTIONAL & PET OWNERS & 9 & 5.0000 & 1.2247 & .4082 \\
SCALE & NON-PET OWNERS & 9 & 4.8889 & 1.4530 & .4843 \\
\hline MENTAL HEALTH & PET OWNERS & 9 & 25.2222 & 4.8419 & 1.6140 \\
SCALE & NON-PET OWNERS & 9 & 24.3333 & 4.6904 & 1.5635 \\
\hline BODILY PAIN & PET OWNERS & 9 & 8.267 & 2.822 & .941 \\
SCALE & NON-PET OWNERS & 9 & 8.344 & 2.329 & .776 \\
\hline
\end{tabular}

Table 1B

Independent Samples Test

\begin{tabular}{|l|c|c|c|c|}
\hline \multirow{2}{*}{} & \multicolumn{4}{|c|}{ t-test for Equality of Means } \\
\cline { 2 - 5 } & $\mathbf{t}$ & $\mathbf{d f}$ & $\begin{array}{c}\text { Sig. } \\
\text { (2-tailed) }\end{array}$ & $\begin{array}{c}\text { Std. Error } \\
\text { Difference }\end{array}$ \\
\hline PHYSICAL FUNCTIONING SCALE &. .043 & 16 & .966 & 2.5880 \\
\hline ROLE-PHYSICAL SCALE & .735 & 16 & .473 & .7556 \\
\hline GENERAL HEALTH SCALE & .813 & 16 & .428 & 2.3222 \\
\hline VITALITY SCALE & .222 & 16 & .827 & 2.5031 \\
\hline SOCIAL FUNCTIONING SCALE & .743 & 16 & .468 & 1.0467 \\
\hline ROLE-EMOTIONAL SCALE & .175 & 16 & .863 & .6334 \\
\hline MENTAL HEALTH SCALE & .395 & 16 & .698 & 2.2471 \\
\hline BODILY PAIN SCALE & -.064 & 16 & .950 & 1.220 \\
\hline
\end{tabular}




\section{References}

Anderson, W. P., Reid, C. M., \& Jennings, G. L. (1992). Pet ownership and risk factors for cardiovascular disease. The Medical Journal of Australia, 157, 298-301.

American Nurses Association. (1996). Scope and standards of advanced practice registered nursing. Washington, DC: American Nurses Publishing.

Bauer, N. K. (1993). The world of the golden retriever: A dog for all seasons. Neptune City, NJ: T. F. H. Publications, Inc.

Beck, A. \& Katcher, A. (1983). Between pets and people: The importance of animal companionship. New York: G. P. Putnam's Sons.

Blackman, D. (1996). Furry friends fact sheet [On-line].

Available: http://wnw: furm.friends.org/patsfact.hum.

Bodmer, N. M. (1998). Impact of pet ownership on the well-being of adolescents with few familial resources. In Wilson, C. C. \& Turner, D. C. (1998). Companion animals in human health. Thousand Oaks, CA: SAGE Publications, Inc.

Brickel, C. M. (1979). The therapeutic roles of cat mascots with a hospital-based geriatric population: A staff survey. The Gerontologist, 19, (4), 368-372.

Chumley, P. R., Gorski, J. D., Saxton, A. M., Granger, B. P., \& New, Jr., J. C. (1994). Companion animal attachment and military transfer. Anthrozoos, 6 (4), 258-273.

Churchill, M., Safaoui, J., McCabe, B. W., \& Baun, M. M. (1999). Using a therapy dog to alleviate the agitation and desocialization of people with Alzheimer's disease. Journal of Psychosocial Nursing, 37, (4), 16-22. 
Corson, S. A., Corson, E. O'L., Gwynne, P. H., \& Arnold, L. E. (1977). Pet dogs as nonverbal communication links in hospital psychiatry. Comprehensive Psychiatry, 18, (1), 6172.

Cusack, O. (1988). Pets and mental health. New York: The Haworth Press.

Fick, K. M. (1993). The influence of an animal on social interactions of nursing home residents in a group setting. The American Journal of Occupational Therapy, 47, (6), 529-534.

Friedmann, E., Katcher, A. H., Lynch, J. J., \& Thomas, S. A. (1980). Animal companions and one-year survival of patients after discharge from a coronary care unit. Public Health Reports, 95, (4), 307-312.

Goldston, L. (1999, August 2). Animal friends: Gentle mascot enlivens seniors residence. San Jose Mercury News, p. 5C.

Gorin, S. S. \& Arnold, J. (1998). Health promotion handbook. St. Louis, MO: Mosby, Inc.

Heath, S. (1999). Duty and the beasts. Nursing Times, 95, (15), 32-33.

Kongable, L. G., Stolley, J. M., \& Buckwalter, K. C. (1990). Pet therapy for Alzheimer's patients: A survey. Journal of Long Term Care Administration, 18, (3), 17-21.

Lago, D. (1998). Conceptual frameworks for human-animal bond research: A commentary. In Wilson, C. C. \& Turner, D. C. (1998). Companion animals in human health. Thousand Oaks, CA: SAGE Publications, Inc.

Price, C. L. (1996). Patients improve with pet therapy. Texas Medicine, 92 (8), 12-13.

Raina, P., Waltner-Toews, D., Bonnett, B., Woodward, C., \& Abernathy, T. (1999). Influence of companion animals on the physical and phychological health of older people: An 
analysis of a one-year longitudinal study. Journal of the American Geriatric Society, 47, 323329.

Robin, M., \& ten Bensel, R. (1985). Pets and the socialization of children. Marriage and Family Review, 8, 63-78.

Robinson, I. (1999). Pet therapy. Nursing Times, 95 (15), 33-34.

Schindehette, S., \& Wescott, G. C. (1999). Where there's a will. People Magazine, 52 , (15), 62-67.

Serpell, J. (1991). Beneficial effects of pet ownership on some aspects of human health and behaviour. The Royal Society of Medicine, 84, (12), 717-720.

Shiely, J. C., Bayliss, M. S., Keller, S. D., Tsai, C., \& Ware, J. E. (1996). $\underline{\text { SF-36 health }}$ survey annotated bibliography: First edition (1988-1995). Boston: The Health Institute, New England Medical Center [On-line]. Available: http://nww.sf-36.com.

Snyder, M. \& Lindquist, R. (1998). Complementary/alternative therapies in nursing. New York: Springer Publishing Company, Inc.

Teeter, L. M. (1997). Pet therapy program: Proposal for the US Department of Health and Human Services. Journal of the American Veterinary Medical Association, 210, (10), 14351438.

Triebenbacher, S. L. (1998). The relationship between attachment to companion animals and self-esteem: A developmental perspective. In Wilson, C. C. \& Turner, D. C. (1998). Companion animals in human health. Thousand Oaks, CA: SAGE Publications, Inc.

U. S. Census Bureau (1999). Statistical abstract of the United States: The national data book. $\left(119^{\text {th }} E d\right.$. $)$.Washington, DC: Author. 